present a considerable resemblance to "Grocco's triangle." Its broad base would be found just above the twelfth rib and it would taper gradually up to tbe second dorsal vertebra.

That this is the explanation of "Grocco's triangle" I do not for a moment pretend; but that it may be a factor of some importance in producing left-sided dulness in right-sided effusions must be patent to everyone who studies the accompanying diagrams.

Cairo.

\section{EXCISION OF THE PAROTID GLAND WITH PRESERVATION OF THE FACIAL NERVE; ITS POSSIBILITY.}

By T. OARWAKDINE, M.S., M.B. Lond., F.R.C.S. ENG., HONORARY BURGEON TO THE BRISTOL ROYAL INFIRMARY.

As far as I am aware there is no recorded attempt to remove the whole of the parotid gland with the preservation of the facial nerve. The following example, in which the operation was performed successfully, may encourage others to preserve the movements of the face in certain cases when removing the parotid gland. The question is rather an important one; for, unlike the conditions which obtain when the main trunk of the facial nerve is injured, there is no possibility of performing any kind of nerve anastomosis after injury to the ramifications of the facial nerve passing through the parotid gland. The distal filaments are too small to join with any other motor supply.

In 1905 a girl, aged 18 years, was under my care for a mixed tumour of the parotid gland which was shelled out so as not materially to damage the nerve. But it commenced to return two months afterwards and the patient came under

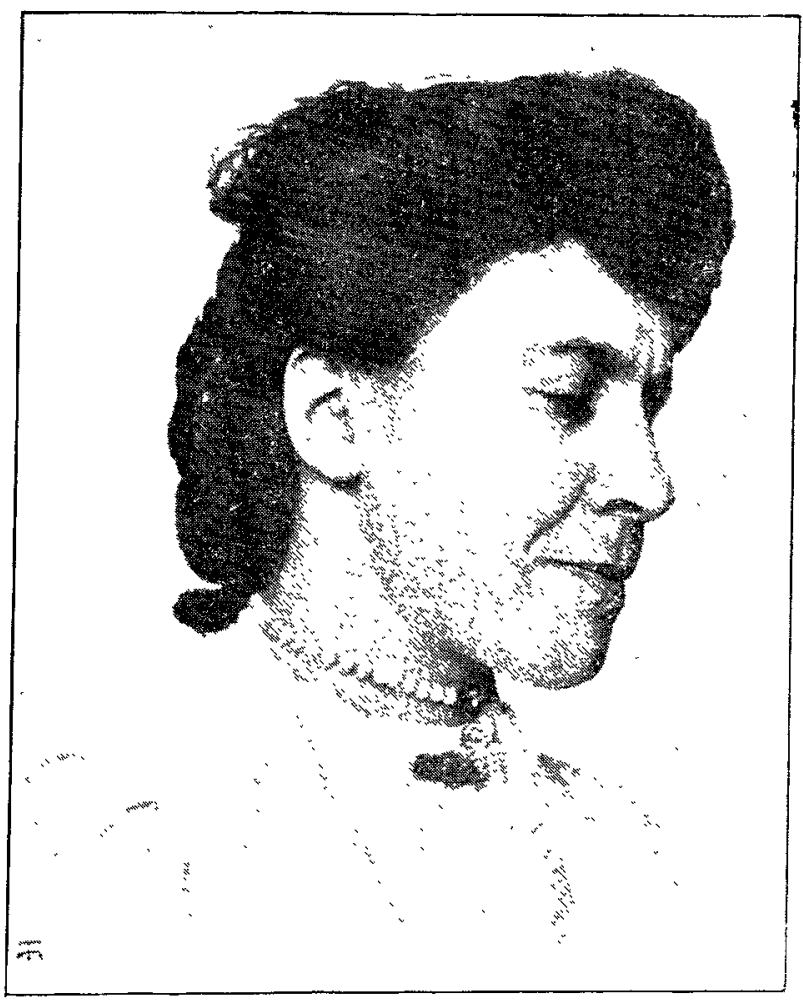

Patient after operation, showing the extent of contraction possible in the facial muscles.

my care again in May, 1906, with a tumour of the size of a large walnut. I proposed to her that I would make the attempt to dissece up the facial nerve and its branches first, and then to remove the whole of the parotid gland. By patient dissection with small sharp scalpels the nerve was successfully freed and held up by a loop of catgut, then the vessels were tied above and below, and the whole gland was completely excised. One or two distal filaments were accidentally ruptured, but the greater part of the nerve was preserved. Following the operation there was temporary facial paralysis, but in a couple of months the patient had twitchings at the angle of the mouth and kinæsthetic sensations. In about four months she had some movement of the facial muscles about the eye and mouth. A year afterwards she had good control of the facial muscles of that side, with very occasional slight twitchings. At this time very little inequality in the movements of the two sides of the face was discernible and the extent to which the patient could move the facial muscles of the side of the operation is depicted in the accompanying reproduction of a photograph which was taken during the phase of contracture.

The operation requires the expenditure of considerable time and care but the cosmetic results repay the trouble.

Bristol.

\section{THE INCREASE OF DISEASES OF THE NERVOUS SYSTEM AND OF INSANITY.}

By WILlIaM W. IRELAND, M.D. EDIN.

Ir is a subject of common remark that in the present day there is a greater strain upon the nervous system, and this begins at an earlier period of life. The overtaxing at the schools, the increased amount of irksome study men have to go through in order to gain entry into the professions, the greater anxiety and hurry of life, the restlessness induced by the increased facilities of intercommunication, are all additional causes of irritation and depression. There is a craving for a variety of excitements and enjoyments, and a growth of artificial wants and a greater difficulty of earning sufficient wage and keeping up under incessant competition. The diffusion of education amongst all ranks, the struggles of aspiring persons amongst the poorer classes to rise in the world, the discontent and bitter wars of labour, entailing many disputes and frequent strikes and breaches of contract, the spread of the coopperative movement which is rendering the position of the private shopkeeper more difficult to hold, and the formation of big companies which crush out small businesses, - all these and some social antagonisms on which we have no time to $d$ well go to make this a harder and less agreeable world to many. At the same time the new conditions of our to-day life are not without their compensations. If ve move about more we obtain more frequent amusement and change of air; if letters or telegrams too often claim our attention and disturb our repose, they often banish uncertainty and anxiety. Sounder views on dietetics have become known and drunkenness has become less prevalent The decrease in intemperance in liquor awnongst the middle and upper classes during the last half century has been very marked, and there is reason to believe tbat this decrease is extending to the lower classes. In general, we lead more secure lives than our fathers did, live under better laws, and have less to fear from injustice and oppression. There can be no doubt that during the last half century the condition of the working classes has greatly improved, their wages are doubled, while the purchasing power of money has increased for most articles, and they live under much better sanitary conditions. The result has been a notable dimination of the death-rate both in England and Scotland during the last quarter of the century. Nevertheless, it appears to me that the strain upon the nervous system is getting greater, at least for the middle and upper classes, and that therefore we may expect more nervous derangements and breakdowns. But to make a general opinion like this evident by exact inquiries is, on the face of it, very difficult.

Seven years ago I addressed to a number of medical men of experience and reputation the following queries: 1 . Have you found since you began to practise medicine that there has been an increase in the relative frequency of diseases of the nervous system? 2. Have new forms come into prominence? 3. Have you observed any chavge in the type of old diseases? The answers which I received were far from settling the questions. Some physicians of great experience stated that they had noticed no increase in the relative frequency of nervous diseases; others were of opinion that nervous diseases had increased in frequency during the last 20 years. From all the answers which I have received I should judge that there has been no noticeable increase in nervous diseases in the country districts and in small towns, but there is some evidence that there has been an increase in those complaints in large towns, especially in functional disorders such as neurasthenia. Probably this increase affects some classes and persons of special parsuits more

1 A paper read at the International Congress of Psychiatry and Neurology, at Amsterdam, on Sept. 5th, 1907. 